\title{
Fruit and Vegetable, Sugar-Sweetened Beverage Consumption among Kindergartners in Accra Metropolitan Area, Ghana: A Cross-Sectional Study
}

\author{
Perdita Hilary Lopes ${ }^{1,2,{ }^{*} \text {, Donne Kofi Ameme }}{ }^{2,3}$, George Kuma Khumaloo ${ }^{2,3}$, Nana Afia Ntim ${ }^{2,4}$, \\ Rexford Adade $^{2}$, Phoebe Balagumeyetime ${ }^{2,3}$, Evans Nsor Ayamdooh ${ }^{1,2}$, Patrick Akandi ${ }^{1,2}$, \\ Maame Amo-Addae ${ }^{2,3}$ \\ ${ }^{1}$ Department of Epidemiology, Veterinary Services Directorate, Accra, Ghana \\ ${ }^{2}$ Department of Epidemiology and Disease Control, School of Public Health, University of Ghana, Accra, Ghana \\ ${ }^{3}$ Department of Public Health Surveillance and Disease Control, Ministry of Health, Accra, Ghana \\ ${ }^{4}$ Department of Virology, Noguchi Memorial Institute for Medical Research, University of Ghana, Accra, Ghana \\ Email address: \\ pehilopes@yahoo.com (P.H. Lopes), amemedonne@yahoo.com (D. K. Ameme), edieadade@gmail.com (R. Adade), \\ drkhumalo@yahoo.com (G. K. Khumaloo), vistabuena2010@gmail.com (E. N. Ayamdooh), babyilarv@yahoo.com (N. A. Ntim), \\ phoebebala55@yahoo.com (P. Balagumyetime), dr.patrickakandi@yahoo.com (P. Akandi), mamoaddae@gmail.com (M. Amo-Addae) \\ ${ }^{*}$ Corresponding author
}

\section{To cite this article:}

Perdita Hilary Lopes, Donne Kofi Ameme, George Kuma Khumaloo, Nana Afia Ntim, Rexford Adade, Phoebe Balagumeyetime, Evans Nsor Ayamdooh, Patrick Akandi, Maame Amo-Addae. Fruit and Vegetable, Sugar-Sweetened Beverage Consumption among Kindergartners in Accra Metropolitan Area, Ghana: A Cross-Sectional Study. European Journal of Preventive Medicine. Vol. 6, No. 4, 2018 , pp. 53-57. doi: 10.11648/j.ejpm.20180604.13

Received: April 29, 2018; Accepted: September 5, 2018; Published: October 6, 2018

\begin{abstract}
Background: Fruit and vegetable consumption (F\&VC) provide important nutrients and greatly reduces the risk of non-communicable diseases, especially when started from childhood. F\&VC among adults in Ghana is one of the lowest worldwide, and this may also pertain to children. Since school children spend considerable time in school, what they eat during school hours is important for their development. The objective of this study was to assess F\&VC and the proportion of sugarsweetened beverage consumption (SSBC) among two socio-economic classes. Methods: A cross-sectional study of kindergartners in the Accra Metropolitan Area was carried out. Fruits, vegetables, sugar-sweetened beverages and two socioeconomic classes were defined prior to the study. Six schools were randomly selected; two each from three sub-metros from the Accra-Metropolitan Area. Data on meals eaten by 422 kindergartners were collected through observation and interview, guided by a checklist. Means and percentages were calculated. F\&VC and SSBC was assessed along the two socio-economic classes. Results: Feeding options at school were home-packed, school-provided, and meals sold by vendors. The mean age of the respondents was 4.1 years, with $49.1 \%(207 / 422)$ being male. The proportion of kindergartners who consumed schoolprovided and home-packed meals was $70.1 \%(296 / 422)$ and $64.5 \%$ (272/422) respectively. Only 2.2\% (9/422) of kindergartners consumed fruits, whereas total vegetable consumption was $34.1 \%(144 / 422)$. SSBC was associated with socioeconomic class (95\% CI 0.28-0.62). Conclusions: F\&VC was generally low in the study population. SSBC was high, especially, in kindergartners from the higher socio-economic class schools. The Ghana Education Service should promote their consumption, by making fruits and vegetables available in schools.
\end{abstract}

Keywords: Fruits, Vegetable, Sweetened Drink, Consumption, School Children, Ghana, Non-Communicable Diseases

\section{Introduction}

Fruits and vegetables are the sources of important vitamins and essential minerals which are beneficial to the body. The consumption of diets rich in fruits and vegetables have been known from epidemiological studies to decrease mortality risk 
from non-communicable diseases (NCD's) such as cancer and ischemic heart disease, and type 2 diabetes mellitus [1-5]. Some studies also suggest that increasing fruit and vegetable consumption (F\&VC) to about $600 \mathrm{~g}$ per day could potentially reduce global mortalities due to stomach and oesophageal cancers, ischemic heart disease, and ischemic stroke significantly [6-8]. This protective benefit of fruit and vegetable consumption (F\&VC) is enhanced when started from childhood $[2,9]$. Indeed low F\&VC is cited among the 10 top risk factors for global mortality, and is therefore hardly surprising that an estimated 2.7 million lives could potentially be saved annually with sufficient F\&VC [10]. In consonance with this, the WHO launched a global campaign to increase F\&VC [10]. Similarly, the Government of Ghana, through the Ministry of Health $(\mathrm{MoH})$, embarked on health promotion under the "Regenerative Health" drive, which includes promoting the significant consumption of fruits and vegetables as part of the normal daily food intake [11]. There is also abundant literature on the link between sugar-sweetened beverages consumption and childhood obesity, a precursor for diabetes and other non-communicable diseases [12, 13]. A systematic review by Hall et al. placed F\&VC among adults in Ghana at a low level compared to most other countries. Of 52 countries studied, the prevalence of F\&VC was lowest in Ghana whereas Pakistan scored highest; $36.6 \%$ and $99.2 \%$ for men, and $38 \%$ and $99.3 \%$ for women respectively in the two countries. This was shown to increase with age and income [14]. Since dietary habits are formed in the first twenty years of life, habits acquired during childhood may extend into adulthood $[9,15,16]$. Additionally, the better part of the growing years of school children are spent away from home, since they spend long hours in school [17]. For this reason, what they eat during school hours will form a significant proportion of their daily food intake and hence, impact on their general health. It is therefore important that a substantial part of the diet children consume in school contain fruits and vegetables in order to inculcate healthy eating habits in them from an early age and thereby reduce the risk of acquiring NCD's later in life. However, the level of F\&VC among school children in Ghana is not well known. The objective of this study therefore was to assess the consumption of fruits and vegetables, and sugarsweetened beverages among kindergartners in the Accra Metropolitan Area. Specifically, to compare F\&VC among kindergartners (aged 3-9 years) across two different socioeconomic strata, and also, compare the proportion of kindergartners consuming fruits and vegetables with the proportion consuming sugar-sweetened beverages (SSB).

\section{Materials and Methods}

\subsection{Study Design}

A cross-sectional study of kindergartners in the Accra Metropolitan Area (AMA) of the Greater-Accra Region (GAR) of Ghana was done. A checklist was used to collect data on meals eaten by kindergartners and their source through observation and interview.

\subsection{Sample Size Calculation, Sampling and Selection Criteria}

Assuming a proportion of interest $\mathrm{p}$ of $50 \%$ at $95 \%$ confidence interval (CI) and 0.025 degree of precision (d), and allowing for sampling errors, a final sample size of 422 was used. High and low socio-economic schools were defined; schools with fees above 100 Ghana cedis per term were classified as belonging to high socio-economic class and those paying 100 Ghana cedis or less were designated as low socio-economic class. Simple random sampling was used to select three educational sub-metros out of nine in the AMA in close proximity to the University of Ghana, from each of which three clusters of schools were identified. Stratified, random sampling was applied to select two schools, one each from schools of high and low socio-economic status using the amount of school fees paid per term to determine the socio-economic background of the children, and also, based on the number of desired pupils in the class (68-70). Altogether, six schools were thus selected and the lunches of kindergartners observed during mealtime on the $8^{\text {th }}$ of September, 2011.

\subsection{Definition of Fruits, Vegetables, Sugar-Sweetened Drinks and Kindergartners}

Fruits were described as any fresh, whole, peeled, pasteurized, conserved fruits or pure fruit juice without sugar added, whether locally produced or imported. Vegetables included all locally available varieties (excluding cooked tomatoes) whether raw, cooked, or pasteurized. Sugarsweetened drinks were defined as any juice made either from fruit juices or artificially-flavored drinks with sugar added. Kindergartners were described as school children in nursery $1-2$.

\subsection{Data Analysis}

Data was entered into Microsoft Excel, cleaned and exported to Epi Info 3.5.3. Means and percentages were calculated and expressed as graphs. Comparisons and associations, were made between F\&VC among kindergartners with respect to socio-economic class, as well as $\mathrm{F} \& \mathrm{VC}$ and $\mathrm{SSBC}$.

\subsection{Ethical Clearance}

Permission was sought through the School of Public Health, University of Ghana, Legon, and from authorities of the participating schools to conduct the research. The teachers or those who were in charge of the children's food opened their school meals or lunch bags for the researchers to observe the content.

\section{Results}

\subsection{Univariate Analysis}

The meals of a total of 422 kindergartners were observed in the study, $49.1 \%$ of who were male. Their mean age was 
$4.1( \pm$ SD 1.0) years, with a median of 4.0 years. There were 206 and 216 kindergartners from the high and low socioeconomic classes respectively.

\subsection{Sources of Food Eaten by Kindergartners in Schools}

The highest proportion of kindergartners, 70.1\% (296/422) ate school-provided meals, whereas $64.5 \%(272 / 422)$ brought food from home.

\subsection{Consumption of Fruits, Vegetables and Sugar- Sweetened Drinks by Kindergartners}

The proportion of kindergartners who consumed fruits, vegetables and sugar-sweetened drinks were $2.1 \%$, (9/422), $34.1 \%$ (144/422), and 43.1\% (182/422) respectively. All the sugar-sweetened drinks and fruits were home-provided. Four $(0.9 \%)$ of the kindergartners brought food which included vegetables from home.

\subsection{Sugar-Sweetened Drink Consumption by Socio-Economic Class}

Of the number of kindergartners who consumed sugarsweetened drinks, $61.0 \%(111 / 182)$ were from the higher socio-economic class, and this was statistically significant (95\% CI, 0.28-0.62) as shown in Table 1.

Table 1. Sweetened-drink consumption by kindergartners by socio economic class.

\begin{tabular}{llll}
\hline Social class & Do not consume & Consume & Total \\
\hline High & 95 & 111 & 206 \\
Low & 145 & 71 & 216 \\
Total & 240 & 182 & 422 \\
\hline
\end{tabular}

\subsection{Fruit and Vegetable Consumption by Socio-Economic Class}

Of the number of children who ate fruits, 56\% (5/9) were from the higher socio-economic class $(95 \%$ CI, Fishers exact test, 0.47), whereas an equal number of kindergartners from both socio-economic classes consumed vegetables, 72/144 each (95\% CI, 0.62-1.39). Only $0.5 \%$ of respondents $(2 / 422)$ consumed both fruits and vegetables, and both were from the higher socio-economic class.

\subsection{Availability of Fruits in the School Environment}

Only one out of the six participating schools (16.67\%) made fruits available for children to purchase from fruit vendors, whereas sugar-sweetened drinks were sold by school-authorized vendors in all six schools.

\section{Discussion}

A higher proportion of kindergartners, 65.4\% (276/422), regardless of socio-economic class, are neither eating fruits nor vegetables. This finding reflects what is known in the older population. In a study of fruit and vegetable consumption among adolescents from 49 low and middle income countries, less than $30 \%$ met the WHO recommendations for $\mathrm{F} \& \mathrm{VC}$ [18], whiles a similar study among secondary school students in Surulele, Lagos State, Nigeria, also reported only $5.8 \%$ of respondents consumed fruits and vegetables [19]. However, it is in sharp contrast to that of a meta study in which low socio-economic status was associated with low F\&VC [20]. In this study, the low level of F\&VC in the study population could perhaps, be attributed to non-availability of fruits in the school environment, or the majority of parents not providing fruits in the lunch packs of children, or both. The proportion of children eating fruits in the higher socio-economic class is higher than in the lower class: $56 \%$ and $44 \%$ respectively, however this difference is not statistically significant (CI 95\%, Fisher's exact test 0.47 ). Similarly, there is no significant difference between the two socio-economic classes with respect to F\&VC. From the results, since $70.1 \%(296 / 422)$ and $64.5 \%$ (272/422) of kindergartners ate school-provided and home-cooked foods respectively, it can be can concluded that, the number of kindergartners who took both school and home-provided meals were $34.6 \%(146 / 422)$. Further, if only $34.1 \%$ of kindergartners ate vegetables, and $0.9 \%$ brought vegetables from home, then it follows that schools provided about $97.4 \%$ of the total vegetables consumed. This implies that parents leave the consumption of vegetables by their children to school authorities. Not only was SSBC high among the kindergartners, but also, associated with socio-economic class; a higher proportion of pupils from the higher socioeconomic class consumed sugar-sweetened drinks. This may be probably due to affordability or because it is in vogue. Similar studies also found high SSBC among young school going children, as well as an association between SSBC and social class [21, 22, 23]. Additionally, the high number of kindergartners drinking sugar-sweetened beverages all brought them from home, implying that parents influenced the consumption of SSB by making it available in their lunch boxes. This is similar to other studies where parents played a key role in the consumption of sugar-sweetened beverages by their children by making it available [24, 25]. The finding of higher SSBC and low F\&VC is also in consonance with the findings of a California study in which higher consumption of vegetables was positively associated with lower levels of SSBC [26].

\subsection{Strengths and Weaknesses of the Study, and in Relation to Other Studies}

The strength of the study lies in being able to get a baseline information as to whether children are consuming fruits and vegetables in the first place. It also gave us a preview into the sources of food eaten by children in schools. A weakness was that the study did not cover other regions. Also, since the study was just a snap shot, we cannot say for sure that on other days, fruits and vegetables are not served in the meals of school children.

\subsection{Meaning of the Study}

The study has highlighted the fact that our children are not 
consuming fruits and vegetables in their growing years and could therefore be lacking micronutrients important for their development and body functions, and this might predispose them to non-communicable diseases in the near future. On the contrary, parents and school authorities are encouraging the consumption of fuzzy drinks by making them available. Also, since a higher proportion of pupils ate school provided food $(70.1 \%)$, it would be a good avenue to introduce any intervention in the dietary habits of school children in general. Poor diet could adversely affect the academic performance of school children [15, 27]. In this study, higher consumption of vegetables in children was found to have a positive influence on the reduced consumption of SSBs.

\subsection{Unanswered Questions and Future Research}

The study was largely qualitative; it only established that the level of F\&VC in kindergartners is low but it was unable to determine if the quantities being consumed meets standard nutritional guidelines as was done in a similar study in nine European countries. A more detailed quantitative research has to be carried out to determine whether what they are consuming is adequate.

\subsection{Conclusion}

Fruit and vegetable consumption was generally low in the study population. Sugar sweetened beverages consumption was high especially in kindergartners from the higher socioeconomic class. It is recommended that the Director General of the Ghana Health Service, in collaboration with the Ministry of Education, should strengthen public education on the benefits of fruits and vegetable consumption, especially in school children. The Minister of Education should ensure that the benefits of F\&VC are taught in the school curriculum. Parents should substitute the inclusion of sweetened drinks with fruits in the lunch boxes of children. Following the dissemination of the findings of this base study, two of the participating schools have already introduced fruits and vegetables on school premises for purchase by school children.

\section{Competing Interests}

The authors declare that they have no competing interests

\section{Acknowledgements}

We wish to acknowledge all the lecturers of the Ghana Field Epidemiology and Laboratory Training Programme, School of Public Health, University of Ghana, Legon, for their guidance and direction which made this research possible. Special gratitude goes to Dr. Kofi Mensah Nyarko, Prof. Edwin Afari, Dr. Frederick Wurapa Dr. S. O. Sackey, and Dr. Patricia Akweongo for their mentorship. We also thank all the school children, head teachers, class teachers and caregivers of participating schools for their immense cooperation which made this study possible.

\section{References}

[1] Crowe F. L., A. W. Roddam, T. J. Key, P. N. Appleby, K. Overvad, M. U. Jakobsen (2011). Fruit and veggetable intake and mortality from isheamic heart disease: results from the European prospective Investigation into Canccer and Nutrition (EPIC)-Heart study. European Heart Journal 32(10):1235-43.

[2] Dauchet L., P. Amouyel, S. Hercberg, J. Dallongeville. Fruit and vegetable consumption and risk of coronary heart disease: a meta-analysis of cohort studies (2006). Journal of Nutrition: 136(10):2588-93.

[3] Appel L. J., T. J. Moore, E. Obarzanek, W. M. Vollmer, L. P Svetkey, F. M. Sacks (1997). A clinical trial of the efffects of dietary patterns on blood pressure. New England Journal of Medicine; 336(16):1117-24.

[4] Ness A. R., J. W. Powles (1997). Fruit and vegetables and cardiovascular disease: a review. International Journal of Epidemiology; 26(1):1-13.

[5] Carter P., L. J. Gray, J. Troughton, K. Khunti, M. J. Davies (2010). Fruit and vegetable intake and incidence of type 2 diabetes mellitus: systematic review and meta-analysis. British Medical Journal 19; 341:c4229.

[6] Lock K., J. Pomerleau, L. Causer, D. R. Altmann, M. McKee (2005). The global burden of disease attributable to low fruit and vegetable consumption: implications for the global strategy on diet. 83(2) 100-8. Bulletin of World Health Organization; 83(2):100-8.

[7] Ledoux T. A., M. D. Hingle, T. Baranowski (2011). Relationship of fruit and vegetable intake with adiposity: a systematic review. Obesity Reviews; 12(5):e143-150.

[8] Cooper A. J., N. G Forouchi, Z. Ye, B. Buijsse, L. Arriola, B. Balkau (2012). Fruit and vegetable intake and type 2 diabetes mellitus: a meta-analysis of prospective cohort studies. European Journal of Clinical Nutrition; 66(10):10821092.

[9] Sivasankaran S (2010). The cardio-protective diet. Indian Journal of Medical Research; 132(5):608-16.

[10] Fruit and Vegetable Promotion Initiative/ A meeting Report/25-27/08.03. Geneva, Switzerland; 25-27/08/03. Report No.: WHO/NPH/NNP/00.

[11] Ministry of Health, Ghana (2002). Programme of Work for Ministry of Health, 2002-2006.

[12] Ludwig D. S., K. E. Peterson, S. L. Gortmaker (2001). Relation between consumption of sugar-sweetened drinks and childhood obesity: a prospective, observational analysis. Lancet London England: 17; 357(9255):505-8.

[13] Malik V. S., M. B. Schulze, F. B Hu (2006). Intake of sugarsweetened beverages and weight gain: a systematic review. American Journal of Clinical Nutrition; 84(2):274-88.

[14] Hall J. N., S. Moore, S. B. Harper, J. W. Lynch (2009). Global variability in fruit and vegetable consumption. American Journal of Preventive Medicine: 1; 36(5):402-409.e5.

[15] Feinstein L., R. Sabates, A. Sorhaindo, I. Rogers, D. Herrick, $\mathrm{K}$. Northstone (2008). Dietary patterns related to attainment in school: The importance of early eating patterns. Journal of Epidemiology and Community Health 62(8):734-9. 
[16] Park S., Pan L, B. Sherry, R. Li R (2014). The association of sugar-sweetened beverage intake during infancy with Sugarsweetened beverage intake at 6 years of age. Pediatrics: 1; 134(Supplement 1):S56-62.

[17] Iruka I., P. Carver (2006). Initial Resultts from the 2005 NHES Early Childhood Program Participation Survey (NCES 2006-075). The National Centre for Education Statisitcs; 2006.

[18] Darfour-Oduro, S. A., D. M. Buchner, J. E. Andrade, D. S. Grigsby (2018). A comparative study of fruit and vegetable consumption and physical activity among adolescents in 49 low-and middle-income countries. Scientific Reports; 8(1683).

[19] Silva, O. O., Ayankogbe, O. O., Odugbemi, T. O. (2017). Knowledge and consumption of fruits and vegetables among secondary school students of Obele Community Juniour High School, Surulele, Lagos State, Nigeria. Journal of Clinical Science; 14, 68-73.

[20] Rasmussen M., R. Krølner, K-I. Klepp, L. Lytle, J. Brug, E. Bere, et al (2006). Determinants of fruit and vegetable consumption among children and adolescents: a review of the literature. Part I: quantitative studies. International Journal of Behavioural Nutrition and Physical Activity; 11;3(1):22.

[21] Rampersaud G. C., L. B. Bailey, G. P. Kauwell (2003). National survey beverage consumption data for children and adolescents indicate the need to encourage a shift toward more nutritive beverages. Journal of The American Dietetic Association; 103(1):97-100.
[22] Cullen K. W., D. M. Ash, C. Warneke, C. de Moor C (2002). Intake of soft drinks, fruit-flavoured beverages, and fruits and vegetables by children in grades 4 through 6 . American Journal of Public Health; 92(9):1475-8.

[23] Bleisch, S. N., K. A. Vercammen, J. W. Kom, L. Zhonghe (2017). Trends in beverage consumption among children and adults 2003-2010. Obesity; 26(2)42-441.

[24] Bere E., G. E. Sørli, S. Velde Te, K. Klepp (2007). Determinants of adolescents' soft drink consumption. Public Health Nutrition; 11(1):49-56.

[25] Grimm G., L. Harnack, M. Story (2004). Factors associated with soft drink consumption in school-aged children. Journal of American Dietetic Association: 104(8):1244-9.

[26] Keihner AJ, Linares AM, Rider CD, Sugerman S, Mitchell PR, Hudes M. Education, Diet, and Environmental Factors Influence Sugar-Sweetened Beverage Consumption Among California Children, Teens, and Adults. Available at: center for wellness and nutrition.org/wp_content/uploads/2015/05/SugarSweetenedbe veragesResearchBrief.pdf.

[27] Florence M. D., M. Asbridge, P. J. Veugelers (2008). Diet Quality and Academic Performance. Journal of School Health; (78):209-15. 